\title{
The Impact of Microfinance on Household Livelihood in Red Sea State Sudan
}

\author{
Ahmed Mohammed Bilal1, Adam Mohammed Ibrahim Brroy¹, Nahid Alamin Ibrahim² \\ ${ }^{1}$ Economics Department, Port Sudan Ahlia College, Port Sudan, Sudan \\ ${ }^{2}$ Languages Department, Ahlia College, Port Sudan, Sudan \\ Email: ahmedblal@yahoo.com, Adambrroy2014@gmail.com, Nahidibrahim7272@gmail.com
}

How to cite this paper: Bilal, A. M., Brroy, A. M. I., \& Ibrahim, N. A. (2020). The Impact of Microfinance on Household Livelihood in Red Sea State Sudan. Theoretical Economics Letters, 10, 281-291. https://doi.org/10.4236/tel.2020.102018

Received: October 18, 2019

Accepted: March 31, 2020

Published: April 3, 2020

Copyright (c) 2020 by author(s) and Scientific Research Publishing Inc. This work is licensed under the Creative Commons Attribution International License (CC BY 4.0).

http://creativecommons.org/licenses/by/4.0/

(c) (i) Open Access

\begin{abstract}
The study examined the impact of microfinance on livelihood the main objective of the paper is to investigate and analyze the impact of micro finance on house hold livelihood in Red Sea State. In methodology the study used econometric and descriptive statistical analytical method. Using the regression equations. We examined the time series data as important step that is overlooked by many studies and research. The series graph showed the instability (non-stationary) in order to address the variance of the variance; we obtained the natural logarithm of the series data. Thus we obtained the estimates of the parameters of model as well as the counter logarithm (anti-log) using the ordinary liner simple method. It is the efficient way to obtain an efficient regression. We avoided the false regression (spurious regression) forecasting data series in the future and this is the most important of this paper. The results indicate that there is a positive impact between the increase of microfinance and livelihood.
\end{abstract}

\section{Keywords}

Livelihood, PASED, Micro-Finance, the Poor, Red Sea State

\section{Introduction}

The main focus of this study is to investigate and analyze the impact of micro finance on household livelihood in Red Sea State.

Microfinance has become an important instrument for poverty alleviation in developing countries through its provision of both the financial services and non financial services to the poor.

Microfinance: is described as the provision of appropriate financial services to significant numbers of Low income, economically active people with an end ob- 
jective to alleviate poverty.

Livelihood: comprise the capabilities, assets (Including both material and social resources) and activities required for a means of living. A livelihood is sustainable when it can cope with and recover from stress and shocks and maintain or enhance its capabilities and assets both now and in the future, while not undermining the natural resource base (Chijoria, 2000).

The World Bank defines poverty as inability to attain a minimum standard of living. Poverty means a shortage of having enough to eat, low life expectance, a higher rate of infant mortality, low education standard, low enrolment and opportunities, poor drinking water, inadequate health care, unfit housing conditions and lake of active participation in decision making process.

The Red Sea State Rural areas inhabitants depended basically on animal husbandry and subsistence agriculture as primary livelihood systems. Other secondary livelihood systems include; charcoal production, wood cutting, casual labour, petty trade, mining, handcrafts and government or private sector employment (Aziz, 2010).

The post-conditions of the serve drought of mid eighties led to major changes in the traditional systems and resulted in a high displacement rate of rural population.

The majority of population of Red Sea State is today experiencing serve livelihoods erosion and increasing vulnerability (Babiker, 2006).

The most vulnerable groups are among the remote rural communities, especially those whose livelihood is dependent on livestock rearing. Households with limited access to land and livestock such as who have displaced by drought or conflict are particularly vulnerable.

Income in rural areas of Red Sea State is currently estimated to stand 93 us $\$$ per annum. Furthermore, as much as $92 \%$ of the population currently Lives beneath the dollar a day poverty Line ((UNDP) Report, 2009).

In the previous years, various efforts have been made by the Sudanese government and ANGOS to address the issue of poverty, the important one is availability of microfinance service for the poor people in Sudan particularly in Red Sea State. Therefore the livelihood of many household improved. While livelihood of some families remains staple, this poses questions what is the impact of micro finance on people's livelihood?

The port Sudan Association for Small Enterprise Development (PASED) is local NGO established and registered in Red Sea State in October 2000, this as a result of the transformation from ACORD International programme that serve the local red sea community for over 15 years.

PASED is registered at the central bank of Sudan micro-finance unit as anon deposit taking micro-finance institution in 2012. It currently operates in port Sudan city to improve the livelihoods of the low income segment of the economically active people through increased access to financial and non financial services in a sustainable manner and line with the good practices. Since its 
transformation into an independent NGO, PASED has aligned it's programme specializing in urban and rural development and reduction of poverty among poor communities, based on the micro-finance delivery on Islamic banking, to pertain the need of inhabitants of the red sea state it reaches its clients directly through its 6 branches offices, 5 at port Sudan localities located in different sites of the city, and to increase its new markets penetration, one branch opened at Swakin town 70 kilometers south of port Sudan by the end of year 2011 (PASED Report, 2019).

\subsection{Problem Statement \& Justification}

Despite of efforts which have been done from the monetary authority in process of microfinance availability in Sudan and its success, the weak performance of formal financial institutions defeat the general objectives of microfinance policy, the actual implement ratio did not exceed (32\%) from the total microfinance fund 2016 in Red Sea state. Ministry of Finance and UNICEF (2017), this partly due the majority of Red sea state poor does not have access to these institutions, because the poor is unable to provide collateral, they have no documented credit history and they lack basic management, accounting and financial literacy skills.

This study enhances the previous studies, which may have not been properly investigated and understood well the impact of credit on socio-economic status of beneficiaries.

\subsection{Questions of the Study}

- What is the role and impact of microfinance on people's livelihood?

- How does the microfinance contribute to improve beneficiaries' livelihood?

\subsection{The Study Significance}

- In Sudan, several studies have been done on microfinance institutions, but it has not been properly investigated and understood well the impact of micro credit on livelihood.

- A few studies have done on the impact of microfinance on livelihood for example (Manahil, 2014).

- First, the study will contribute to the body of knowledge on the impact of microfinance on livelihood.

- Second, this study intended to shed light on relation between microfinance and improving livelihood particularly with focus on economic impacts for planners and policy makers in government, agencies and NGOs. This will help them to come out with substantives possible alternative policy interventions which might help to address problems and challenges which micro finance beneficiaries face.

- Third, this study will offer empirical evidence on the impact of micro finance on livelihood for use in short term and long term interventions especially in fight against poverty. 


\subsection{The Study Assumptions}

The study testifies the following assumptions:

1) The Microfinance may affect positively on House livelihood in Red Sea State.

2) There many reasons and barriers impeding the poor Household Accessibility to formal Credit.

\subsection{Objectives of the Study}

1) Assess the impact of Microfinance on Household Livelihood in Red Sea State on Selected livelihood indicators Such as income, improvement in Saving, Household assets, Housing, Access to food;

2) Knowing the relationship between the microfinance and livelihood;

3) Building an econometric equation for planning and forecasting;

4) The study aims to design remediate procedures that facilitate the process of formal credit to household in Red Sea State, knowing the constraints which affect poor Household Accessibility to Formal Financial institutions.

\subsection{Methodology}

The study adopted econometrics and descriptive statistical analytical method.

\section{Literature Review}

Amine Teclay Habte (2016), the study was conducted in rural Areas of Eretria to find out whether saving and micro credit program as a micro finance institution has improved the livelihood of its clients. The specific objectives of study were to describe the characteristic feature of rural livelihood in terms of resources owned, the strategies pursued and outcomes achieved, identify and examine the determinants household participation in the saving and micro credit programe on household livelihood. The study employed aquasi-experimental cross-section survey design involving structured and semi structured questionnaire administered to 500 respondents of whom 200represnted the treated group and 300 the controlled group logit regression was employed to identify the factors that determine household participation in the program. The results indicated that participation in the saving and microcredit program has a significantly higher Average treatment effect on households. Profits generated from off-farm and small micro enterprises, the values of household and livestock assets, food and non food consumption expenditures and nutrition quality, were found to be on average higher for the treated households. Therefore, it could be argued that the provision of micro financial resources has significant positive effects on household livelihood outcomes.

Grace Wakio, Maurice Sakw (2014) the study results indicated that microfinance had effects on the socio-economic status of woman. The study indicated that the access to microcredit service increased income levels, increased stocks 
and Output of enterprise as well as increased expenditure on health and education services.

Slumah Musa (2014), the study aims at dealing with the role of micro-finance polices on decreasing poverty degree in Sudan, with emphasis on saving and social development bank and the agricultural bank of Sudan. The most important hypothesis of the study is that there economical and social impact on weak slices that benefit from these polices. The study attempted in investigating information to perceive the economical and social impact in decreasing poverty acuteness in Sudan, The questionnaire distributed to customers of micro-financing at saving and social development bank and the agricultural bank of Sudan, The study used the statistics program of social studies (SPSS) for data analysis. The study concluded that there is a statistics relation between the micro-finance in decreasing poverty acuteness through improving the economical and social level, and that the policy of micro financing in Sudan has a social and economical impact on the weak slices.

Esmat Ara, Md. Assraf Seddiky, main objective of this study was to investigate the changes in livelihood status of woman beneficiaries of Grameen Bank in Bangladesh. Forty woman beneficiaries of Grameen Bank have been selected a sample from Jhukorganha branch under Jessore district of Bangladesh, employed a simple random sampling method. Study findings reveal that micro credit empowers woman by giving them more control over house hold assets and resources, more freedom and decision making power, and greater access to participation in all spheres of live.

Benedict Anselmi * Jutuce M Gration * and Kennedy F Oriko (2016): The main objective of this study was to find out whether the provision of microfinance services of Rural Initiative and Development Enterprises (PRIDE) has brought changes on livelihood of its clients. The study was carried out PRIDE Tanzania Arusha branch where clients those received credit for more than five years were studied. It focuses on the result of microfinance programme at house level. A case study design was used in this study. A probability sampling technique was adopted in this study to select respondents to be included in this study. Finding revealed that microfinance programme has made a positive impact on household, income, assets ownership and domestic appliances ownership, food condition, education, medical facilities and saving at the house level. Therefore, strengthening the development of microfinance in Tanzania especially in rural areas is an appropriate policy instrument to realize the objectives of poverty Reduction Strategy of Tanzania.

\section{Methods}

The basic step is important in the analysis of econometrics, because it shows the descriptive features of the data such as: the general trend, seasonal changes and non-stationary) and other measurement problems. In spite of the importance of the time series chart, we still notice that some studies and research have reached 
the wrong results as a result of not signing the series graphically or checking to see if the time series has a measurement problem (Figure 1 and Figure 2).

Figure 1 shows that the data suffers from non-stationarity in the time series.

For the two variables studied, and for treating the unevenness of the time series variance in two ways.

First, find the natural logrithm of the variable;

Second: find the square islands of the variable.

We will choose the first method to get rid of measurement problems in this research and then we can get the regression equation, and thus we have avoided the false regression (Spurious Regression) to foresight (Forecasting) series data in the future.

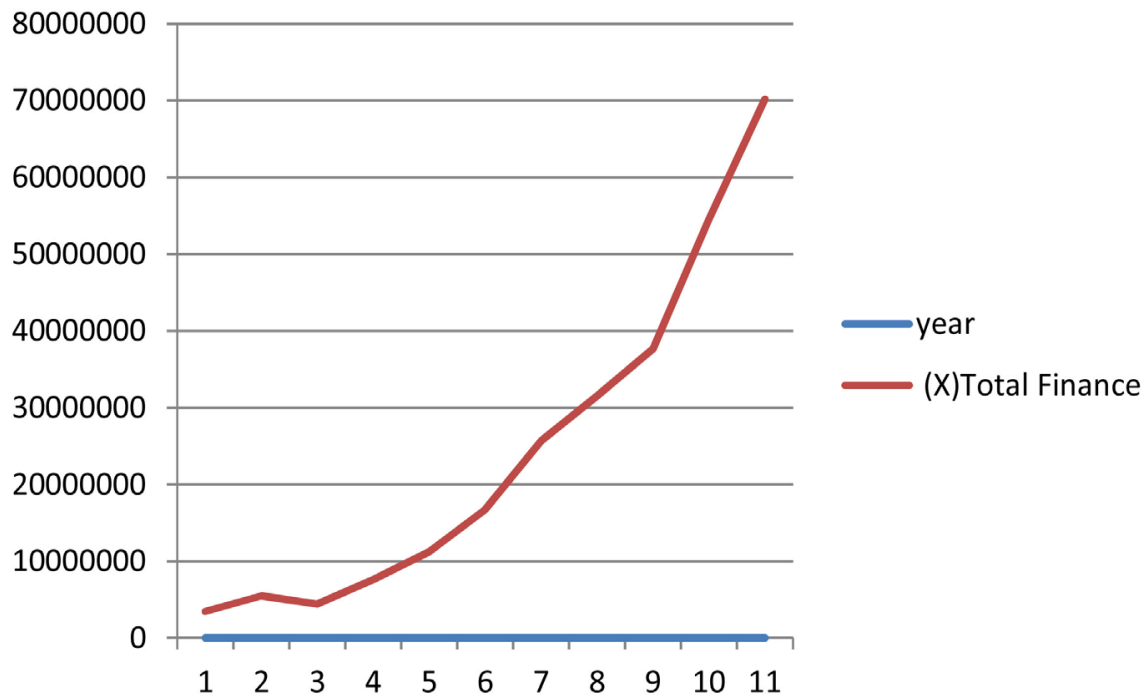

Figure 1. Shows the time series of the independent variable (microfinance).

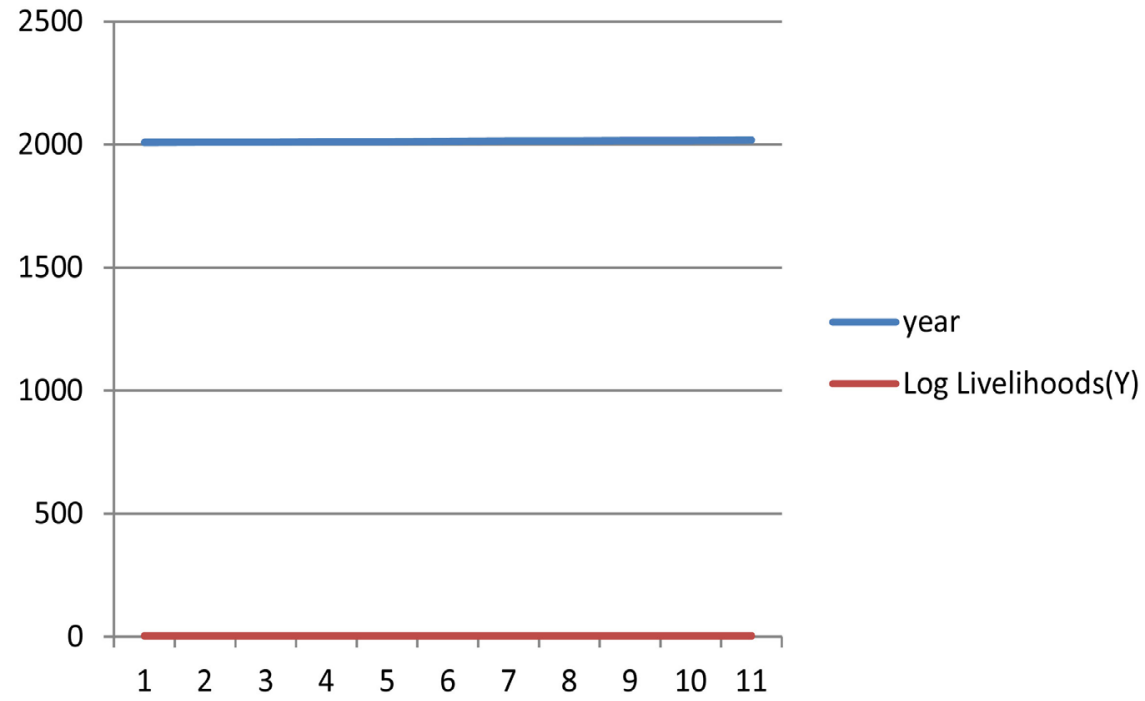

Figure 2. Shows the time series data of the dependent variable (Y) (livelihoods after the natural logarithm). 


\section{Data Analysis}

We suggest a direct linear relationship between microfinance $(X)$ and livelihoods, which can be formulated with the following model:

$$
Y_{1}=b_{0}+b_{1} X_{1}
$$

where: livelihoods $Y$ : microfinance: $X$, lump portion of the vertical axis $(b): b_{0}$,

Sloping: $b_{1}$.

In Equation (1) the relationship of the relationship describes that increasing microfinance leads to increased livelihoods and vice versa. The linearity of the relationship means that if the independent variable microfinance $(X)$ changes by a certain percentage, the dependent variable livelihood $(Y)$ changes by a constant.

$\Delta Y$

If we go to the graph and we like microfinance on the horizontal axis, livelihoods on the vertical axis, and we connect the pairs of observations on the two variables over that time period, we get a straight line. Since there are factors other than internal funding $(X)$ at the standard of living $(Y)$, we do not expect in practice that the pairs of actual observations of the variables $(X),(Y)$ on a straight line. Therefore, we can take into account the effect of other factors, by converting the full mathematical formula in Equation (1) random formula as follows:

$$
Y=b_{0}+b_{1} x+U
$$

To obtain the parameters of the model above we use the data Table 1 in the analysis using SPSS program to obtain the parameters of the model.

Table 2 shows the outputs of the analysis of the parameters of the regression equation:

Table 1. The time series of model variables.

\begin{tabular}{ccccc}
\hline Year & Total Finance $(X)$ & Livelihoods $(Y)$ & Log Total Finance $(X)$ & Log Livelihoods $(Y)$ \\
\hline 2008 & $3,496,709$ & 2495 & 6.54 & 3.40 \\
2009 & $5,522,457$ & 2127 & 6.74 & 3.33 \\
2010 & $4,450,184$ & 3344 & 6.65 & 3.52 \\
2011 & $7,650,686$ & 5459 & 6.88 & 3.74 \\
2012 & $11,257,282$ & 6728 & 7.05 & 3.83 \\
2013 & $16,740,027$ & 7831 & 7.22 & 3.89 \\
2014 & $25,738,281$ & 8905 & 7.41 & 3.95 \\
2015 & $31,531,513$ & 8698 & 7.50 & 3.94 \\
2016 & $37,681,611$ & 8427 & 7.58 & 3.93 \\
2017 & $54,538,478$ & 9401 & 7.74 & 3.97 \\
2018 & $70,188,171$ & 8102 & 7.85 & 3.91 \\
\hline
\end{tabular}


Table 2. Shows the outputs of the analysis of the parameters of the regression equation.

\begin{tabular}{cccccc}
\hline The Model & $R$ & $R^{2}$ & $R^{-2}$ & T. Test & F. Test \\
\hline$Y=3.06+7.43 X$ & 0.871 & 0.759 & 0.732 & 0.787 & 28.304 \\
\hline
\end{tabular}

F. test $\mathrm{T}$. test $\mathrm{R}=2 \mathrm{R} 2 \mathrm{R}$ Form

$28.3040 .7870 .7320 .7590 .871 \quad Y=3.06+7.43 X$

So we conclude that the estimated function of declining livelihoods $(\mathrm{Y})$ over microfinance $(X)$ in Sudan in Red Sea State is as follows:

$$
Y=3.06+7.43 X
$$

The constant of Equation (3) $b_{0}=3.06$ and $b_{1}=7.43$ represents the lump segment (or the intersection) of the estimated livelihood curve $(\hat{Y})$ with the two microfinance axes $(X)$, and the livelihoods independent of microfinance $(X)$. Autonomous, which is determined by factors other than microfinance, we note here that the value of livelihoods ( $Y$ ) (in million pounds) when microfinance is equal to zero.

The slope of the livelihood curve is $b_{1}=\Delta Y=7.43 \Delta X$.

The marginal trend of livelihoods represents MP $(y)$ in Equation (3) and measures the rate of change in livelihoods $(y)$ as a result of the change in microfinance $(X)$ in one unit of measurement. Livelihoods are worth 7,430,000 Sudanese pounds as a result of the increase in microfinance by one million Sudanese pounds.

The correlation coefficient $R=0.87$ indicates a strong positive correlation between livelihoods $(Y)$ and microfinance $(X)$ in Equation (3), and the coefficient of determination $R^{12}=0.76$ shows that $76 \%$ of the total variation (variation) in livelihoods Living $(Y)$ is defined (or interpreted) by our knowledge of the total variations of microfinance $(X)$ in Equation (3), as the indefinite coefficient, $1-R^{2}=1-0.76=0.24$, indicates that $24 \%$ and $75 \%$ represent random variation in Livelihoods $(Y)$ that we could not identify with our knowledge of microfinance $(X)$.

Adjusted $R^{2}=R^{2}=0.732$ is the value of the determinant so that it is not affected by the number of explanatory variables (independent), by taking into account the number of critical degrees, which decrease with increasing the number of interpreted variables (independent), and the determining factor determinants of quality Reconcile the model whenever its value is closer to the correct one.

For the selection of the intrinsic relationship between livelihoods $(Y)$ and microfinance $(X)$, we can use the T. (T. statistic) test whose value is included in the analysis results to test the intrinsic regression coefficient, or use F. (Test). To test the intrinsic coefficient of determination of Equation (3) and the question arises whether to obtain the coefficient $b_{1}=7.43$.

In a random sample drawn from a statistical community where the relationship between microfinance $(X)$ and livelihoods $(Y)$ is zero and the coefficient is $1=0 \beta$, then assume (Figure 3 ).

- Null hypothesis $H_{0}=b_{1}=\beta_{1}=0$. 
- Alternative hypothesis $H_{1}=b_{1}=\beta_{1} \neq 0$.

- $\quad$ T. calculated $=0.787>\mathrm{T}_{2}$. tabulated $(0.05,10)=1.812$

It is worth mentioning that the researcher is able to reach a test result of the fundamental determination of the coefficient as follows:

Imposition of $\mathrm{Nil}: \mathrm{H}_{0}:$ Provides that the decline in livelihoods on microfinance is statistically insignificant.

Alternative hypothesis: H1: It states that the decline in livelihoods on microfinance is statistically significant.

F. Statistical test:

- F. calculated $=28.304<$ F. tabulated $(0.05,9)=2.97$

Comparing the value of $\mathrm{F}$. test obtained from Table 2, calculated by the test obtained from SPSS output, we find that the calculated value is greater than the table value, so we reject nullity and accept the alternative hypothesis which states that the relationship between livelihoods $(Y)$ and finance The younger $(X)$ relationship is statistically significant (Figure 4).

\section{Results}

1) Increase livelihoods as a result of increasing microfinance and vice versa.

2) It is expected that the positive relationship will be positive between increasing microfinance and increasing livelihoods in the same direction.

3) There is a strong explanation relationship between microfinance and livelihoods.

4) The regression equation is a mechanism for setting future plans for microfinance and livelihoods.

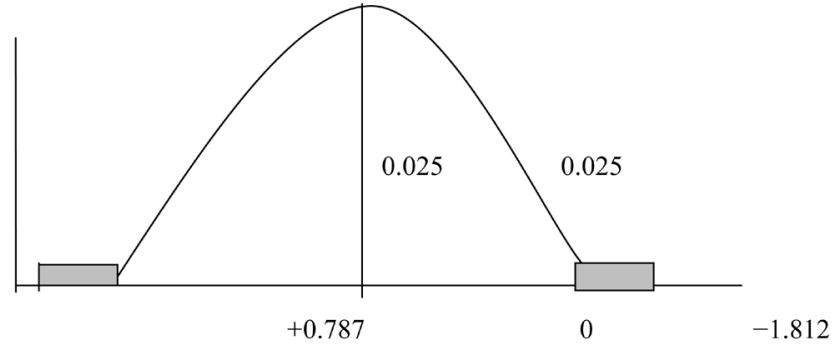

Figure 3. Shows the intrinsic regression coefficient of T. test.

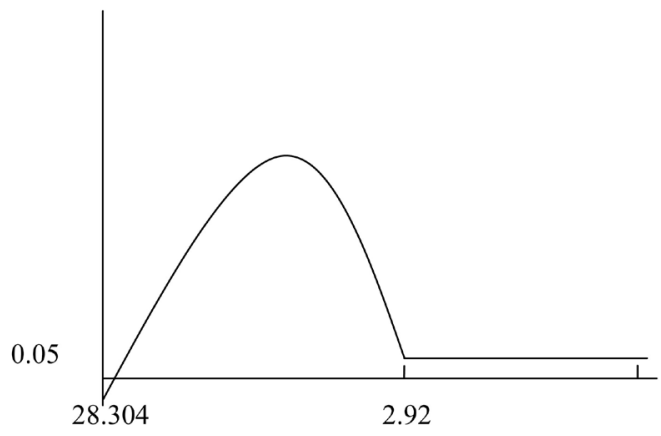

Figure 4. Illustrates the intrinsic coefficient of determining the test (F. test). 


\subsection{Findings}

1) Livelihoods increased nearly sevenfold as a result of increasing microfinance and vice versa.

2) The more microfinance increases the value of livelihoods increases in the same direction.

3) There is a strong explanatory correlation between microfinance and livelihoods.

4) The regression equation showed the expected future values of microfinance and livelihoods.

\subsection{Recommendations}

1) Double the size of microfinance for poor families, which will be positively reflected in doubling production and productivity.

2) Increase the size of microfinance to increase the value of the size of livelihoods in the same direction.

3) Increasing the size of microfinance results in the exit of funded families from the cycle of poverty and increased productivity.

4) The regression equation can be considered a mechanism for setting future strategies for microfinance plans and livelihoods.

5) Continue to train craftsmen and small business owners.

6) Opening new branches in the city's districts, especially the peripheral neighborhoods, to provide financing to the largest possible number of families.

7) Diffusion and entry into new markets in the localities of the state, but gradually.

\section{Conflicts of Interest}

The authors declare no conflicts of interest regarding the publication of this paper.

\section{References}

Aziz, A. A. (2010). Dynamism of Livelihood. Port Sudan: Red Sea University.

Babiker, M. (2006). Addressing Chronic Livelihoods Vulnerability in Red Sea State, Sudan. A Report Prepared for OXFAM GB.

Chijoria, M. M. (2000). The Performance and Sustainability of Microfinance Institution in Tanzania. World Bank Report.

Gration, M., \& Kennedy, F. (2016). The Impact of Microfinance Services to Household Livelihood: A Case Study of PRIDE Arushe Branch. International Journal of Scientific and Research Publication, 6, 166-171. http://www.ijsrp.org

Habte, A. T. (2016). The Impact of Micro Finance on Household Livelihood, Evidence from Rural Eritrea. Thesis Submitted in Partial Fulfillment of Requirements for Degree of Doctor of Philosophy in Department of Economics Faculty of Economic and Management Sciences University of Western Cape.

Manahil, K. A. A. A. (2014). The Role of Microfinance Institutions on Local Community 
Development. Thesis Submitted in Partial Fulfillment of Requirements for Degree of Master of Social Science, Faculty of Postgraduate Studies, University of Khartoum.

Ministry of Finance and UNICEF (2017). Socio-Economic Presentation Red Sea State (2012-2016) Collaboration with (UNICEF).

Musa, S. (2014). Microfinance and Its Role in Poverty Alleviation in Sudan. An Applied Study on Bank of Saving and Social Development and Agricultural Bank. Thesis Submitted in Partial of Requirement for Doctor of Philosophy in Faculty of Postgraduate Studies, University of Sudan for Sciences and Technology.

Port Sudan Association for Small Enterprise Development PASED (2019). Financial and Statistical Performance Report.

UNDP Report (2009). Red Sea State Situation Analysis.

Wakio, G., \& Sakwa, M. (2014). Socio-Economic Effects of Microfinance Services on Woman, the Case of ROSWO Microfinance, Nakuru County, Kenya. International Journal of Academic Research in Economics and Management Sciences, 3, 43-59. https://doi.org/10.6007/IJAREMS/v3-i3/902 